\title{
J $\mathbf{0}$ u $\mathbf{r}$ n a l
}

für die

\section{reine und angewandte Mathematik.}

I n z w a nglose $\mathrm{l}$ He f te $\mathrm{n}$.

\author{
Herausgegeben \\ von \\ A. L. $\quad \mathbf{C}$ e $\mathbf{I}$ I e.
}

Mit thătiger Befơrderung hoher Koniglich-Preufsischer Behorden.

Zwei und funfzigster Band.

In vier Heften.

Mit drei lithographirten Tafeln.

Berlin, 1856.

Druck und Verlag von Georg Reimer. 
